\title{
Human motivation and professional practice: of knights, knaves and social workers
}

\author{
Graham P. Martin, Kay Phelps \& Savita Katbamna
}

Efforts to improve the efficiency and responsiveness of public services by harnessing the selfinterest of professionals in state agencies have been widely debated in the recent literature on welfare state reform. In the context of social services, one way in which British policy-makers have sought to effect such changes has been through the "new community care" of the 1990 NHS and Community Care Act. Key to this is the concept of care management, in which the identification of needs and the provision of services are separated, purportedly with a view to improving advocacy, choice and quality for service users. This paper uses data from a wideranging qualitative study of access to social care for older people to examine the success of the policy in these terms, with specific reference to its attempts to harness the rational self-interest of professionals. While care management removes one potential conflict of interests by separating commissioning and provision, the responsibility of social care professionals to comply with organizational priorities conflicts with their role of advocacy for their clients, a tension rendered all the more problematic by the perceived inadequacy of funding. Moreover, the bureaucracy of the care management process itself further negates the approach's supposedly client-centred ethos.

Published in:

Social Policy \& Administration 38(5): 470-487

http://www.blackwellpublishing.com/journal.asp?ref=0144-5596

http://www.blackwell-synergy.com/links/doi/10.1111/j.1467-9515.2004.00402.x/abs/

doi:10.1111/j.1467-9515.2004.00402.x

\section{Introduction}

The reconstitution of the welfare state has received much academic attention in recent years. Whilst many accounts focus on the social and economic transitions that have precipitated such changes, one influential contribution has been an analysis of a transformation which might be viewed as more endogenous to the domain of social policy: a claimed shift in policymakers' conceptions of the fundamental factors underlying human motivation. Le Grand (1997) argues that where once those charged with the management and delivery of public services were regarded as benevolent, public-spirited 'knights', the dominant view now among policymakers is of public servants as 'knaves' motivated more by self-interest than by the 'greater good' in itself.

In this paper, we examine Le Grand's thesis using data collected in a major study of local authorities' policies and practices regarding the provision of social care. The delivery of personal social services in Britain underwent a major restructuring in the early 1990s on the basis of a national reconsideration of policy which in many ways exemplified the kinds of changes considered by Le Grand. As an area of welfare which has always been subject to rationing according to need and ability to pay, social care represents an intriguing field in which to study the ways in which overarching policies regarding the deployment of resources are translated into practice, and the microsociology of decisions about which clients get what services (cf. Lipsky 1980). Here we look to build upon the existing literature about policy and practice in social services provision (e.g. Chevannes 2002; Ellis et al. 1999; Rummery and Glendinning 1999), but with a somewhat different focus: the extent to which the community care reforms of a decade 
ago have been successful in harnessing managers' and practitioners' self-interest for the greater good in the manner that Le Grand suggests was intended (cf. Kendall et al. 2003). What becomes apparent, we argue, is that policymakers' preconceptions of the motivations of professionals actually themselves serve to generate those motivations: the behaviour of the state, in the form of policy and the way it is implemented, creates knights, knaves and pawns of its servants.

\section{Recent shifts in social policy and the 'Knights, knaves and pawns' thesis}

Much has been written about the social, cultural and economic changes which in the last few decades have transformed the modern societies of the industrial West upon which the postWorld War II welfare states were built. Trends and transitions such as unemployment, the fragmentation of traditional family structures, increased participation of women in the labour market and the unremitting disparity in earnings have rendered the traditional model of the welfare state increasingly inappropriate to the needs of contemporary society, while the unwillingness of taxpayers to accept a requisite burden of taxation has undermined the post-War welfare settlement. The result, as Taylor-Gooby (2000: 7) has it, is that "modern welfare systems call on private sources of finance and provision (through fees, private-public partnerships, the regulation and sometimes the subsidy of private provision) in a wide range of areas." Le Grand (1997) outlines two primary processes through which this shift has been effected: the introduction of competition into welfare provision through such policies as quasi-marketization, and the supplementation of 'fiscal' welfare (redistribution through taxation and social security) with 'legal' welfare, to include such initiatives as the New Deal and the minimum wage, which involve state intervention in the employment market to 'make work pay'.

For Le Grand (1997), though, these parallel shifts represent more than a straightforward response to the perceived failings of the old welfare regime. Rather, they signify a fundamental shift in policymakers' assumptions about the nature of human motivation and behaviour. Le Grand argues that the architects of the welfare state of the 1950s assumed that those working in providing public services were motivated by their desire to aid their fellow citizens. Similarly, taxpayers were supposed by those policymakers to be willing to accept a growing burden of progressive taxes because they were motivated by a collectivist vision of social justice and the amelioration of the plight of the less well-off. In Le Grand's lexicon, then, both groups were seen by policymakers as altruistic 'knights' motivated by a benevolent, social democratic ethic of 'improving society'. Meanwhile, in an intellectual climate that prioritized structure over agency in explaining the plight of the poor, recipients of public services were characterized as the passive, grateful recipients of whatever the state provided. They were, in other words, 'pawns'.

In the last two decades or so, these views of the funders, providers and recipients of the services of the welfare state have been challenged with vigour. Taxpayers are seen by commentators on the Left and Right as increasingly resistant to redistributive policies, while the population as a whole is now characterized as increasingly reflexive and informed, and hence demanding of public services: no longer the pawns of the post-War settlement. Meanwhile, "scepticism grew concerning the belief that bureaucrats and civil servants necessarily operated in the public interest, and that professionals were only concerned with the welfare of their clients" (Le Grand 1997: 158). In the view of policymakers, and indeed of the public at large, then, people-funders, providers and recipients of state services alike-were neither knights nor pawns but 'knaves': self-interested actors who would (to mix metaphors) respond to carrots and sticks designed to reward or punish particular kinds of behaviour. For Le Grand (1997), then, recent social policy has been based on a crucial shift in assumptions about human motivation so that efforts to harness self-interest for the 'greater good' are privileged over a reliance on publicspirited altruism. ${ }^{1}$ Incentives intended to engage the perceived knavish instincts of public servants could be used to promote many agendas, from promoting clients' interests to ensuring compliance with organizational priorities. As we shall see, in community care, the incentives

${ }^{1}$ This is not, though, exclusively the case in all fields of welfare: see for example Le Grand (2002). 
were designed to embrace both of these — though not without significant tensions.

\section{Knights and knaves and community care}

In many ways, the early-1990s reforms of community care policy were exemplary of the kinds of shifts in the thinking of policymakers to which Le Grand (1997) refers. Of particular note among the professed aims of the White Paper which preceded the 1990 National Health Service and Community Care Act were the objectives

- "to make proper assessment of need and good case management the cornerstone of high quality care,

- to promote the development of a flourishing independent sector alongside good quality public services,

- to clarify the responsibilities of agencies and so make it easier to hold them to account for their performance, and

- to secure better value for taxpayers' money by introducing a new funding structure for social care." (Department of Health 1989: 5)

In different ways, each of these accords strongly with the kinds of policy reforms identified by Le Grand as signifying a switch from a 'knight-and-pawn' view of human motivation to more 'knavish' assumptions among policymakers. The quasi-marketization of social services implied by the second aim, and the more rigorous auditing and surveillance of practitioners suggested by the third, are particularly emblematic of trends throughout British social policy in the late 1980s and early 1990s, and beyond. Quasi-markets are to introduce competition between providers of public services, making them more responsive to the demands of purchasers, and compelling them to use resources more efficiently and introduce novel and innovative ways of meeting need.

The counterpart to quasi-marketization of provision as envisaged in the 1989 White Paper and 1990 Act was the introduction of care management and needs-led assessment on the commissioner/purchaser side. Through the assessment and management process, social care practitioners would identify their clients' needs, and then meet these by purchasing appropriate services from providers, thereby tailoring care packages to individuals. By means of care management and the purchaser-provider split, then, social care practitioners would be put in a position where they would be more able to act as advocates for the needs and wishes of the clients, rather than performing the role of both assessor and provider as the 'knights' of the previous regime. The reconceptualization of knights as knaves embodied in the Community Care Act was not, then, as far-reaching as the introduction of, say, GP fundholding, which gave doctors a direct stake in the financial success of their practices. Rather, it aimed to make care managers more responsible and responsive, as guardians of their clients' self-interest: a kind of 'knavery-by-proxy' which complemented efforts to empower users more directly. ${ }^{2}$

It is important to recognize, though, that for all the rhetoric about placing clients at the centre of the process of care planning and delivery, the main driver which led to the 1990 Act was a concern with public expenditure (Parker et al. 2000), stemming from an Audit Commission report (1986) on the inefficient use of residential over community care due to perverse incentives in the social security system (note the fourth aim listed above). Thus even as the White Paper envisaged a future of client-centred, needs-led assessment and care management, the financial concerns of policymakers were apparent:

The aim of assessment should be to arrive at a decision on whether services should be provided, and in what form. Assessments will therefore have to be made against a

\footnotetext{
${ }^{2}$ The extent to which the self-interest of the users themselves (now conceptualized as knaves rather than inert, unthinking pawns) is also harnessed depends on the degree and scope of client consultation involved in the particular model of care management practised, although it is worth noting that user and carer involvement was among the stated intentions of the 1990 Act and of various thrusts of health and social care policy since.
} 
background of stated objectives and priorities determined by the local authority. Decisions on service provision will have to take account of what is available and affordable. Priority must be given to those whose needs are greatest. (Department of Health 1989: 20)

The strategy of moving towards the more 'knave-oriented' policy of needs- rather than serviceled, managerialist social care provision was thus intended also to improve efficiency by ensuring that the greater needs were being prioritized over the lesser-with overall expenditure capped at a given level. In the words of the House of Commons Health Committee (1993: 3), this represented "a fundamental shift from a demand-led system, based on individual entitlement, at given income levels, to one based on the assessment of need, but within a fixed budget."

Thus care management was introduced both to improve responsiveness to clients and to achieve cost containment and rational prioritization. Care management as it has been put into practice has been a multiplicitous beast (e.g. Challis et al. 2001; Weiner et al. 2002), in the absence of a single model of best practice. Guidance issued on implementation (Department of Health 1991a, 1991b) left many areas to the discretion of individual social services departments, giving rise to significant divergence between local authorities in care management practice (McGrath et al. 1996). This kind of variation has marked effects on the results of the process, evident in the six areas that were investigated in our study. The significant point for the moment, however, is that needs-led assessment and care management represent efforts to harness the (assumed) knavish instincts of social care practitioners on behalf of their clients, where previously, such professionals would have acted as both assessors and providers - a potential conflict of interests if those professionals were not the benevolent knights assumed under the previous regime. At the same time, though, care managers also now had a more direct responsibility for the costefficient deployment of the social services budget, a role with its own potential conflict with the interests of the client. The efficient use of resources, achieved through the rational 'knavery' of effective care management based on the identification and prioritization of needs, was to be the means through which these two aims were reconciled-but with what success?

\section{The 'Access to social care' project}

The primary data used in this paper are from a study on access to social care for older people carried out by the Nuffield Community Care Studies Unit in partnership with Help the Aged from November 1999 to April 2002, funded by the Community Fund (NCCSU 2002). The aims of the study were

- to identify local authorities' (LAs') policies and practices regarding the allocation of resources for community care services for older people,

- to identify the polices and practices which have a negative effect on the welfare and quality of life of older clients, and

- to describe the outcomes of these policy and practice decisions by examining their impact on the quality of life of older people at home or in long-term care.

Six LAs were purposively selected for the study to include as diverse a sample as possible, on the basis firstly of deprivation levels and spending on social services, and then according to secondary criteria, including the proportion of the population aged over 65 , the proportion from ethnic minorities, the political profile of the LA and whether it provided free home care, among others. Some of the characteristics of the six LAs selected are indicated in table 1.

In each LA, documents relating to budgets, charging, eligibility, joint-working and the care management process were collected, in-depth interviews and focus groups with professionals were carried out, and in-depth interviews were carried out with service users. This paper draws primarily on the staff interviews and focus groups. ${ }^{3}$ Interviews were conducted with those

${ }^{3} \mathrm{~A}$ total of 81 interviews and focus groups took place with staff across the six LAs. Twenty-three with senior social services managers and 33 with frontline social services staff were supplemented 


\begin{tabular}{lccccc|}
\hline Location & $\begin{array}{c}\text { Spend ratio (social } \\
\text { services) }\end{array}$ & $\begin{array}{c}\text { Townsend } \\
\text { index }\end{array}$ & $\begin{array}{c}\text { Proportion of } \\
\text { population over 65 }\end{array}$ & $\begin{array}{c}\text { Dominant political } \\
\text { party on council }\end{array}$ \\
\hline LA1 & South-east & 1.7 to 1.8 & Low & $10-15 \%$ & Conservative \\
LA2 & North-east & 1.0 to 1.1 & High & $15-20 \%$ & Labour \\
LA3 & London & 0.9 to 1.0 & High & $10-15 \%$ & Labour \\
LA4 & Midlands & 1.2 to 1.3 & High & $15-20 \%$ & Labour \\
LA5 & Wales & 1.5 to 1.6 & Low & $20-25 \%$ & Labour \\
LA6 & South-west & 1.1 to 1.2 & Low & $20-25 \%$ & Liberal Democrat \\
\hline Table 1: selected characteristics of the six LAs in the Access to Social Care study. Spend ratio \\
indicates the budgeted net revenue expenditure (BNRE) on social services divided by the centrally \\
determined Standard Spending Assessment (SSA) (i.e. the higher the figure, the greater the \\
amount that LA spends on social services relative to the amount allocated for that purpose by \\
central government). Only LA3 had a lower BNRE on social services than its SSA. (Note that \\
figures are given as a range to protect anonymity of participating LAs.) \\
\hline
\end{tabular}

involved at every level of management and practice within the LAs, as well as representatives of independent sector organizations and health service professionals and practitioners. Interviewees were asked about, inter alia, the social services budget and financial pressures, meeting service user needs, policy on services for older people, and outcomes.

The focus of the analysis of the Access to Social Care study was the effects of financial pressures on policy and practice for social services departments (SSDs) in LAs. For the purpose of this paper, information from the original professional interviews was re-analysed to identify themes spanning the six LAs relating to 'knightly' or 'knavish' behaviour according to Le Grand's theory.

\section{The 'new community care' and knights, knaves and pawns}

Much of the substance of the interviews and focus groups was of interest when considered in relation to the changing context of social policy as constructed by Le Grand (1997) and others. Though our research agenda was to do with more general, and perhaps less 'high-level', issues of policy, practice and outcomes as they were pursued in specific local settings, matters of professional conduct in changing organizational contexts were often close to the centre of the themes explored. This gave rise to some intriguing insights into the impacts of changing policy on the practice of health and social care on the ground, though perhaps not, as we shall see, in exactly the way Le Grand's exposition of 'knave-oriented' social policy might anticipate.

\section{Care management}

As detailed above, then, the introduction of care management had two objectives: to make professionals more responsive to the requirements of service users, and to make them more responsive to the organizational concerns of their employers - in particular by making them more accountable for the fixed budgets of social services, and thus requiring them to prioritize between competing needs to balance those budgets. For some budget-holders and senior managers, these two objectives were closely allied:

"There was a political philosophy that when you reached 65 you should have a home help. We've gradually changed that but it's a slow process." (Assistant Director of Social Services, LA2)

"We were able to reduce the number of people going into nursing care, because they didn't really need to be in nursing care, but residential care with support from district nursing. We were already trying to think in terms of this more independence idea,

by four with senior community health service staff, seven with frontline community health service staff, and seven each with private and voluntary sector care providers. These were parttranscribed, and analysed in depth using the 'framework' approach as described in Ritchie and Spencer (1994). 
and shifting people down the care spectrum. [...] People were getting into residential nursing care without an assessment, and didn't really, shouldn't need that level of care." (Finance manager, LA2)

For this respondent, then, maintaining control over a limited budget was an objective logically pursued alongside other, purportedly more 'client-oriented', aims, such as the promotion of independence. Needs-led assessment informs prioritization, which permits an optimal distribution of limited resources in the most equitable manner possible. Some practitioners, however, found the task of reconciling financial constraint with the aim of meeting clients' needs and acting as their advocates more difficult. As a reviewing officer in LA3 explained in relation to residential care placements,

“There are and there aren't choices-I must admit we try to make it easier for ourselves with placements that will take our funds, and ask people to view those. So the choices are there but only what we think, what we are willing to pay for."

Similarly with domiciliary care, social services professionals tended to feel that financial concerns had to take priority over the clients' needs:

"They are less funded as in there is less variety, less choices: it is assumed that if they are bored during the day, they should go to a centre, end of story. [...] If they are unable to get themselves into bed, we put them to bed-that's it you know, not that they want to go out in the middle of the night-go to the pub, go to a social club at night, the choices are not there-it's almost, we're dictating what they need." (Reviewing officer, LA3)

The first priority for the knave of the new regime, then, was to meet organizational targets, such as budgetary requirements; the interests of clients were of secondary importance. Thus the clients themselves remained 'pawns', despite the attempts at 'empowerment by proxy' through the advocacy of their care managers:

"If I was honest I would say that [care plans] are influenced by what services are available. [...] I'm sure that the assessments are needs-led but I think that the care plan and the choice that people have may necessarily be-well, if there were other choices available I'm sure they'd get a better service." (Social worker, LA2)

To some extent, these concerns could be seen in terms of the difficulty of separating 'need' per se from 'need for a (specific) service' (cf. Parry-Jones and Soulsby 2001). However, practitioners could not easily escape the spectre of tight budgets that were perceived to be tightening further. Indeed, in LA5, the first memo to staff from the recently appointed Director of Social Services had stated that staff wilfully overspending their budgets would face disciplinary action.

To the extent that these professionals were being rendered knaves, then, their principal concern was for keeping to budget. Clearly this is a valid aim, but one which, for many professionals, was being accomplished at the expense of the role of advocacy. In the form of various kinds of top-down directives, it was made clear to professionals what their priority must be. Such was the level of central control in certain LAs that some officers found their professional discretion compromised:

"If there's a request for a fee waiving, the finance department always asks us to do a reassess, which I really object to 'cause I don't think it's any of the charging panel's business: they're her needs and that's what she requires." (Care manager, LA5)

Arguably what we see here, then, is a knight recast not as a knave at all, but as a pawn, whose professional judgement is rendered marginal by organizational priorities and decrees from above. And this is an element of the 'new community care' which is reinforced in other aspects of its implementation. 


\section{Eligibility criteria}

The concern of policymakers in the early days of the implementation of the Community Care Act was that SSDs were failing to manage their budgets carefully enough, resulting in a sub-optimal use of resources. In sharp contrast to the more recent scenario depicted above, early reports found that "most authorities were spreading their resources too thinly, finding it difficult to refuse services to even the lowest priority cases" (Association of Metropolitan Authorities 1995; cited in Audit Commission 1996: 11). In response to this failing, the Audit Commission (1996) recommended, inter alia, a clearer delineation of eligibility criteria on the part of LAs. This was to include transparent prioritization of different levels of need to ensure that the greatest be met first, and various processes, such as screening for eligibility before full assessment, designed to help meet this objective.

Eligibility criteria, then, could be seen as a way of making explicit the priorities of the social services department, thereby ensuring equity of provision between and a greater awareness of budgetary limitations. ${ }^{4}$ The data presented so far suggest that they had had some success in this regard; certainly, some of the respondents in our research felt that the existence of criteria made their jobs easier and allowed for a more rational distribution of the LA's limited resources:

"It's not about economy, it's about best value isn't it? There was never a feel that we were having to do the criteria in order to cut down what we provided for people, it was about the best use of the budget." (Social worker, LA2)

At the same time, though, there was a tension for many respondents between the use of eligibility criteria and their own professional judgement. Take, for example, this intriguing interview excerpt:

"When they first introduced [eligibility criteria] I think I and the other OTs were against them. But I think we took on board that there is a need for that, and we don't use them rigidly, we use them as guidelines, so we don't say, 'You do not meet that criteria' if there are circumstances where we think they do. I think then-once we actually got used to using them, I think we were, not relieved, but it's actually quite good to have it officially if you like, it's not me personally saying 'No' to you, it's the department: this is why, and they can have a copy of it, so that actually did help, and I think it does help the most needy to get, you know, it is a form of rationing but that's the reality." (Head Occupational Therapist, LA4)

Whilst stressing the need for flexibility in deploying eligibility criteria, this respondent nevertheless acknowledges that power is being removed from her hands, and even welcomes the abdication of responsibility to a higher level.

Other respondents felt that eligibility criteria had a discernibly negative impact on their ability to meet the needs of their clients effectively and appropriately. Two specific examples must suffice. The first is that of spending caps on domiciliary provision for older people. All six SSDs limited the amount they would pay for providing care in a client's own home, which they applied with varying degrees of strictness. These limits were generally associated with the relative cost of a care home placement for the client, although some LAs discriminated between client groups. ${ }^{5}$ In LA1, the upper limit for domiciliary care for older people was 12 hours per week (though the limit for younger disabled people was 20 hours), which could be exceeded only with the approval of a senior care manager. Other LAs used 'care panels' to decide on cases where the

\footnotetext{
${ }^{4}$ Another approach recommended by the Audit Commission (1996) was budgetary devolution to care managers, to enable them to make rational decisions about provision for their clients based on priority.

${ }^{5}$ As one service manager in LA5 explained, "the reality of it of course is that you have to at some stage agree to a cut-off point. ... Our emphasis is on slightly younger people and therefore it's less palatable to think in terms of institutional care."
} 
spending cap would have to be exceeded to maintain a service user at home. ${ }^{6}$

The rigid use of a cost ceiling to determine provision for a client was ruled illegal by the Local Government Ombudsman in 1996, and to this extent these eligibility criteria demanded a certain degree of discretion on the part of care managers. Expense could never be the sole reason for any decision, and many respondents in our research could give examples of clients living at home with care packages significantly over the formal limit. Nevertheless, it was evident that cost was once again a prominent concern in the conduct of social services professionals. In LA6, for example, one respondent explained the expectations incumbent upon care managers to minimize cost to the department:

"If it was more expensive to stay at home-for example, because of costly nightsitting - we might ask if the family would pay some of the night-sitting themselves, direct to the agency, to avoid residential care. It does happen."

And in LA5, it was clear from the testimony of professionals that money was a crucial factor in any decision about domiciliary care:

"Limits on domiciliary care packages are exceeded [...] only if clients dig their heels in to stay at home. But there have been people who have been forced into care because we've refused to fund them any further. So you can take your risk and stay at home or you can go into care." (Hospital social work team manager, LA5)

Even if the LAs sought to use these criteria only as guidance, what was clear was the significant effect they had on the care managers' ability to act with the interests of clients at the centre of their conduct. What results is not a 'knave-by-proxy' acting as advocate for her or his client, but rather a knavish adherence to organizational needs - or perhaps, again, a pawn, compromised by higher order priorities.

The second substantive example of the impact of eligibility criteria is that of clients with comparatively 'low-level' needs. Given the emphasis on prioritization by LAs in both the Community Care Act and the subsequent review by the Audit Commission (1996) cited above, it is only to be expected that users with comparatively minor needs would receive less provision. ${ }^{7}$ What is of interest, however, is the manner in which such prioritization was practised by the SSDs in our research.

Generally, social services would only fund domestic assistance where clients were in receipt of a package of personal care:

"We used to give help with cleaning and housework and stuff, now if that's all you needed we don't do that-whereas before you would have. [...] You still get it if you've got personal care needs." (Joint-working manager, LA3)

Practitioners and managers were well aware of the potential outcome of denying comparatively independent older people help with such quotidian tasks as shopping and cleaning (cf. Harding 1997):

"We don't do preventative work, which I think is a pity as the local authority doesn't see cleaning as a problem in itself. In months and years ahead these might be the people who will come back to us because there was no preventative work and the place is in a terrible mess." (Reviewing officer, LA3)

In making the receipt of personal care the explicit criterion of eligibility for domestic care, however, LAs pursued a policy that risked missing some of those at greatest risk-quite apart

${ }^{6}$ Conversely, service managers also stated that applications for LA-supported nursing home placements were often also put before the care panel-with a subtext of placing clients in cheaper residential placements wherever possible.

${ }^{7}$ Recent national guidance (Department of Health 2003) has reiterated the need for prioritization, and sought to promote more uniformity and consistency within and between LAs. 
from neglecting the preventive function of domestic assistance. This is best illustrated with reference to an interview with an older couple in LA6. The wife described how they had requested help with shopping and cleaning from social services, but had been automatically refused as neither of them was receiving assistance with personal care. From our encounter with the couple, it emerged that the husband was highly dependent upon his wife for all aspects of his personal care, and that the wife was in poor and declining health herself. The two were keen to support each other as much as possible, but on account of their preference to see to the intimate tasks of personal care themselves, they were disqualifying themselves from any chance of domestic assistance from the LA.

\section{Managerialization and bureaucratization}

What is most striking from this account is the inflexibility with which the eligibility criteria were deployed in the case of this couple. The rule regarding the non-provision of domestic help where no personal care package is in place was applied despite the fact that it was evident from closer examination that this was a high-need, high-risk household.

It strikes us, however, that this case is symptomatic of wider trends in the practice of delivering personal social services which have been cultivated by the reforms of the 1990 Act and by policy pressures since then. This couple's straightforward request for help with domestic chores masked deeper problems which were not recognized by the staff who dealt with the case. It was never explained to them that they might have been entitled to help with personal care; nor was a carer assessment offered to the wife. What appeared to have happened was that the couple's request had been fielded over the telephone by an unqualified worker whose role was to screen referrals according to the eligibility criteria, rather than being dealt with by trained social workers who could look at their needs holistically. The knight had been removed from the screening process, and replaced not by a knave who could weigh up the competing demands on the scarce resources of the department, but rather by a pawn, whose role was simply to filter potential clients on the basis of protocols and check-lists. The process of accessing social services is atomized into a series of discrete, sequential procedures, including this screening stage before assessment.

This is not an unusual feature of the care management process (see, e.g., Hudson 1996; Ware et al. 2003): Department of Health (1991a, 1991b) guidance explicitly divides the process into seven stages, including 'determining the level of assessment'-i.e. a screening of sorts. But breaking down social care into its constituent parts risks undermining the professional discretion of the social worker in gauging complex needs, planning a coherent care package and delivering services based on the individual's particular needs. As one of our respondents suggested,

"Sometimes we deal with the more obvious needs and not with the more disguised ones. Care management tends not to get at some of those deeper needs because I think care management is about arranging and fixing and less and less about therapy." (Team manager, LA1)

To this extent, these kinds of currents seemed to be inherent in the care management process itself. Just as the role of screening can be deprofessionalized, so too can that of provision. Care managers commission providers to meet the discrete identified needs of their clients, and so provision becomes a purely task-oriented undertaking. As one independent domiciliary care provider in LA6 lamented,

"Since the Community Care Act many duties have been reduced to half-an-hour. In a morning, some of our carers can be getting 15 people washed and dressed: you're just running from one to the other."

In the process, any knightly intentions are sidelined; and in place of the knights, again, are pawns, whose duties are restricted to accomplishing the tasks in hand as quickly as possible. Another provider, in LA3, explained that she instructed her carers to try to encourage clients to accomplish tasks for themselves, following a rehabilitative model that might foster independence, 
but that the minimal fees paid for task-oriented social care meant that they simply did not have time to do this and ended up doing the tasks for the clients. Such, though, is the logic of a care management process based on deprofessionalization and (quasi-)market competition between providers for the funds of cash-strapped SSDs.

\section{Knights, knaves or pawns?}

Two principal consequences of the 'new community care' are evident from the testimony and discussion above. The first is the conflict for professionals between the role of custodian of social services' resources and guardian of the interests of their clients. The attempt to harness professionals' knavery for dual purposes frequently results in a situation where the organizational priorities subsume the interests of individual service users; to the extent that professionals are rendered knaves, then, the incentives to which they respond are primarily related to the exigencies of the system. The second consequence, though, stemming from the top-down implementation of the 'new community care', is that they are rendered knaves in only a truncated fashion. Rather than truly harnessing knavery for the greater good, as a means of promoting the optimal use of scarce resources, the managerialist way in which the 'new community care' works frequently creates pawns of the professionals. These are the pawns whose responsibility it is to ensure that the will of the department is carried out, by following the word and rule of eligibility criteria; the pawns who must carry out as much task-oriented social care as quickly as they can, to ensure that their agency can compete for the funds of cash-strapped social services; the pawns whose judgement as social workers and other professionals in assessing users' needs is governed by what services are affordable or even overruled if deemed too expensive.

In considering the self-professed attitudes of some of the professionals we interviewed, then, the primacy of organizational context is evident. What we witness is not the state succeeding in tapping the essential motivation of its servants, but rather the state making knaves or pawns of these professionals by structuring their roles according to its presumptions about their motivation. Consider the following excerpts, which in terms of Le Grand's framework might be taken as examples of an essentially knavish stance on the part of the respondents:

"If a user is assessed as needing a service it is eventually provided, although a delay is sometimes used as a way of refusing, for example, a wheelchair if the user is not going to survive for long." (District nurse, LA2)

"We don't have a priority system for assessments. We're so busy that for a time I just put up a delay because it's too difficult for me to prioritize because they all seem so urgent." (Care manager, LA5)

"Requests for repeat assessments are not granted if a comprehensive assessment has already been carried out except under exceptional circumstances as the client will already be found not to meet the criteria." (Interviewer: "So is there a right to appeal?") "Oh yes, there always is, it's just that we don't necessarily listen to when they knock." (Reviewing officer, LA3)

There are knavish aspects to all three of these quotations, but when they are set in the context of the struggle to balance competing needs in a system with limited resources, it is surely more convincing to argue that the organizational environment is more influential on these actors' behaviour than any sort of 'essential knavery'. The system demands knavish adherence to its rules and procedures, and this is what results (cf. Le Grand 2000).

\section{Discussion}

The 'rationalization' of complex process through bureaucracy is a familiar theme, stemming from Max Weber's original conceit of modernity's 'iron cage' of a highly bureaucratized division of labour (Held 1980; Weber 1922). Herbert Marcuse (1941: 154) takes forward Weber's notion, describing how "individual functions are divided, fixated and synchronized according to [the] objective and impersonal patterns" of technical rationality that increasingly predetermine the 
conduct of bureaucratized tasks. We see in the testimony of our respondents how the rules and procedures of the SSDs' bureaucracies govern the behaviour of professionals as actors, and how the atomization of the care management process demeans the role of professional discretion and sensitivity to individual circumstance. As Marcuse (1941: 142) puts it:

Individual achievement has been transformed into standardized efficiency. The latter is characterized by the fact that the individual's performance is motivated, guided and measured by standards external to him, standards pertaining to predetermined tasks and functions. The efficient individual is the one whose performance is an action only insofar as it is the proper reaction to the objective requirements of the apparatus, and his liberty is confined to the selection of the most adequate means for reaching a goal which he did not set.

Under such conditions, bureaucratic expediency becomes the crucial determinant of professional conduct; knavish self-interest and knightly benevolence are equally constricted by the exigencies of the system. Where the procedures of that system are determined primarily by the need for financial restraint and practical efficiency, efforts to harness the (knavish) inclinations of practitioners succeed only in relation to meeting these organizational outcomes, so that more client-centred outcomes become of marginal relevance, as we see above.

Claims about the fundamental, intrinsic motivations of human individuals are very difficult to substantiate on the basis of empirical evidence, as Le Grand (1997) acknowledges. Some attempts have been made to address this question, through the quasi-experimental 'game theory' of economic psychology (Taylor-Gooby 1999), in the more grounded, empirical context of qualitative research (Taylor-Gooby et al. 2000), and even in the form of 'tick box'-style questionnaire surveys (Kendall 2001). Certainly, though, our data shed no light on the question of whether our respondents are essentially 'knights' or 'knaves' or some combination of the two. We would question, however, the practical usefulness of asking such questions about the fundamental structure of human motivation. One can argue that humans are knights or that they are knaves, or one could argue that human essence is basically malleable and changeable with circumstance. Such arguments are unlikely ultimately to be resolved or answered satisfactorily, and with only dubious empirical evidence either way, they tend towards the detached, abstract and ideological. Simply to aver that humans fit some intermediate position, or that our essence is unfixed, is of itself somewhat banal and, in its way, equally universalizing if one has nothing to say about why or how this is the case. It is only through the study and analysis of how human actors behave in specific social circumstances that we can start to address questions of how and why human behaviour is changeable and context-dependent, questions which seem to us far more relevant to everyday practice. ${ }^{8}$ This requires that we put aside, at least temporarily, the distracting grand narrative of the essential nature of human motivation, in order to focus on the dimensions and dynamics of human behaviours as they occur in practice. Only from this starting-point can we be in a position to say more about the complex, contextually contingent relationship between motivation and behaviour.

In our study, then, what was apparent was the weight of bureaucracy and limited budgets overshadowing the role of knightly or knavish inclinations. Insofar as the incentives of the system did operate effectively, they did so in ensuring a relatively high degree of compliance to budgetary strictures and financial restraint in commissioning. The mode of implementation of

\footnotetext{
${ }^{8}$ Others have sought to begin to address this research agenda. In another paper, Le Grand (2000) himself considers a number of studies presenting varying, to some extent conflicting, evidence about the impact of social context upon motivation, which indicate the breadth of experience with regards to the impact of policy changes upon attitude and behaviour in practice. Kendall et al. (2003) also seek to explore the extent to which the self-professed 'intrinsic' motivations of independent sector domiciliary care providers conform to the 'extrinsic' motivations created by the local social care market, and how this affects the relationships between commissioning social services departments and providers.
} 
the new community care, then, appears to have been successful in the policy's tacit aim of containing expenditure, but at the expense of its declared aim of putting needs and clients first, at least in the contexts of our six LAs. Of course, though, we are not arguing that an explanation based solely on organizational context would be any less moribund than one based solely on supposed essential motivation. Though our data and analysis suggest that bureaucracy and budgeting were significant factors in our respondents' actions, the exceptions to the rule are illustrative of the irreducibility of human behaviour in any context. Private care providers testified to the devotion and dedication beyond the call of duty of their workers, and care managers recounted occasions when they had bent the rules to ensure that a client received the right package, sometimes at considerable risk to their own careers. The fact that these respondents had to work 'outside' the system perhaps indicates how overbearing the system is, although other studies have found the reverse, with 'frontline' practitioners creating their own barriers to provision to manage an overwhelming workload (Chevannes 2002; Ellis et al. 1999; Lipsky 1980; Rummery and Glendinning 1999). What is certainly evident is the diversity of behaviours, which resists straightforward explanations of any hue.

\section{Conclusion}

Cost containment was arguably an overriding aim of the community care reforms of the early 1990s, and so to this extent it should come as no surprise that its effect has pervaded all aspects of the conduct of community care practitioners. The dual, and to some extent conflicting, role of the care manager under such conditions as advocate of the client and guardian of the LA's resources is an inevitable outcome (cf. Lipsky 1980, especially chapters 4 and 11). What we hope we have shown, however, is the way in which the constant spectre of restricted budgets, combined with the transformation of social work into a managerial role of correctly carrying out bureaucratic procedures, has given rise to organizational environments where the needs-led, client-centred approach of professional social work as envisaged in the 1990 NHS and Community Care Act is at best subsidiary to the core objective of minimizing cost, and at worst no more than a myth. In such contexts the potentially progressive dimension of knave-oriented policy through the fostering of a professional commitment to client-centred provision is annulled.

\section{Acknowledgements}

This paper arises from a Community Fund grant and research project conducted in collaboration with Help the Aged. We thank Geraldine Barker, Sylvia Bernard, Sheila Brelivet, Harriet Clarke, Jennifer Francis, Tesni Hadwin, Tanseem Ibrahim, Zubida Jakot, Jenny Ling, Gillian Parker and Billie Shepperson, who worked with us on the project, and the LAs and their staff for their involvement in the research. We would also like to thank Gillian Parker for initiating this paper and providing guidance and encouragement along the way, and Ruth Hancock, Elisabeth Martin, Hilda Parker and an anonymous referee, who read earlier drafts and provided helpful criticism.

\section{$\underline{\text { References }}$}

Audit Commission (1986), Making a Reality of Community Care, London: Audit Commission.

Audit Commission (1996), Balancing the Care Equation: Progress with Community Care, London: HMSO.

Challis, D., K. Weiner, R. Darton, J. Hughes and K. Stewart (2001), Emerging patterns of care management: arrangements for older people in England, Social Policy and Administration, 35, 6: 672-87.

Chevannes, M. (2002), Social construction of the managerialism of needs assessment by health and social care professionals, Health and Social Care in the Community, 10, 3: 168-78.

Department of Health (1989), Caring for People: Community Care in the Next Decade and Beyond, London: HMSO. 
This is an electronic version of an Article published in Social Policy \& Administration 38(5): 470-487. ( 2004 Blackwell Publishing Limited

Department of Health (1991a), Care Management and Assessment: Practitioners' Guide, London: HMSO.

Department of Health (1991b), Care Management and Assessment: Managers' Guide, London: HMSO.

Department of Health (2003), Fair Access to Care Services: Guidance on Eligibility Criteria for Adult Social Care. London: Department of Health.

Ellis, K., A. Davis and K. Rummery (1999), Needs assessment, street-level bureaucracy and the new community care, Social Policy and Administration, 33, 3: 262-80.

Harding, T. (1997), A Life Worth Living: the Independence and Inclusion of Older People, London: Help the Aged.

Held, D. (1980), Introduction to Critical Theory: Horkheimer to Habermas, London: Hutchinson \& Co.

Hudson, B. (1996), Care management: is it working? Community Care Management and Planning, 4, 1: 77-84.

House of Commons Health Committee (1993), Community Care: Funding from April 1993, London: HMSO.

Kendall, J. (2001), Of knights, knaves and merchants: the case of residential care for older people in England in the late 1990s, Social Policy and Administration, 35, 4: 360-75.

Kendall, J., T. Matoševic, J. Forder, M. Knapp, B. Hardy and P. Ware (2003), The motivations of domiciliary care providers in England: new concepts, new findings, Journal of Social Policy 32, 4: 489-511.

Le Grand, J. (1997), Knights, knaves or pawns? Human behaviour and social policy, Journal of Social Policy, 26, 2: 149-69.

Le Grand, J. (2000), From knight to knave? Public policy and market incentives. In P. TaylorGooby (ed.), Risk, Trust and Welfare, Basingstoke: Macmillan, pp.21-30.

Le Grand, J. (2002), The Labour government and the National Health Service, Oxford Review of Economic Policy, 18, 2: 137-53.

Lipsky, M. (1980), Street-level Bureaucracy: Dilemmas of the Individual in Public Services, New York: Russell Sage Foundation.

Marcuse, H. (1941), Some social implications of modern technology. Reprinted in A. Arato and E. Gebhardt (eds) (1978), The Essential Frankfurt School Reader, Oxford: Blackwell, pp.13862.

McGrath, M., G. Grant, P. Ramcharan, K. Caldock, B. Parry-Jones and C. Robinson (1996), The roles and tasks of care managers in Wales, Community Care Management and Planning, 4, 6: $185-94$.

NCCSU (2002), Nothing Personal: Rationing Social Care for Older People, London: Help the Aged.

Parker, G.M., K. Phelps and J. Francis (2000), Access to Social Care for Older People: Literature Review, Leicester: Nuffield Community Care Studies Unit.

Parry-Jones, B. and J. Soulsby (2001), Needs-led assessment: the challenges and the reality, Health and Social Care in the Community, 9, 6: 414-28.

Ritchie, J. and L. Spencer (1994), Qualitative data analysis for applied policy research. In A. Bryman and R.G. Burgess (eds.), Analyzing Qualitative Data, London: Routledge, pp.173-94.

Rummery, K. and C. Glendinning (1999), Negotiating needs, access and gatekeeping: developments in health and community care policies in the UK and the rights of disabled and older citizens, Critical Social Policy, 19, 3: 335-51.

Taylor-Gooby, P. (1999), Markets and motives: trust and egoism in welfare markets, Journal of Social Policy, 28, 1: 97-114.

Taylor-Gooby, P. (2000), Risk and welfare. In P. Taylor-Gooby (ed.), Risk, Trust and Welfare, Basingstoke: Macmillan, pp.1-18.

Taylor-Gooby, P., S. Sylvester, M. Calnan and G. Manley (2000), Knights, knaves and gnashers: professional values and private dentistry, Journal of Social Policy, 29, 3: 375-95.

Ware, T., T. Matosevic, B. Hardy, M. Knapp, J. Kendall and J. Forder (2003) Commissioning care services for older people in England: the view from care managers, users and carers, Ageing and Society 23, 4: 411-28. 
This is an electronic version of an Article published in Social Policy \& Administration 38(5): 470-487. () 2004 Blackwell Publishing Limited

Weber, M. (1922), Bureaucracy. Reprinted in H.H. Gerth and C. Wright Mills (eds) (1991), From Max Weber: Essays in Sociology, London: Routledge, pp.196-244.

Weiner, K., K. Stewart, J. Hughes, D. Challis and R. Darton (2002) Care management arrangements for older people in England: key areas of variation in a national study, Ageing and Society 22, 4: 419-39 